\title{
Eda Kalmre : The Human Sausage Factory. A Study of
} Post-War Rumor in Tartu

[La fabrique de saucisses humaines. Étude d'une rumeur d'après-guerre à Tartu], Amsterdam-New York, 2013, x+180 p.

\section{Véronique Vincent-Campion}

\section{(2) OpenEdition}

\section{Journals}

Édition électronique

URL : https://journals.openedition.org/efo/5554

DOI : $10.4000 /$ efo. 5554

ISSN : 2275-1947

Éditeur

INALCO

Édition imprimée

ISBN : 978-2-343-08571-5

ISSN : 0071-2051

Référence électronique

Véronique Vincent-Campion, "Eda Kalmre : The Human Sausage Factory. A Study of Post-War Rumor in Tartu », Études finno-ougriennes [En ligne], 47 | 2015, mis en ligne le 07 juillet 2016, consulté le 20 septembre 2021. URL : http://journals.openedition.org/efo/5554 ; DOI : https://doi.org/10.4000/efo. 5554

Ce document a été généré automatiquement le 20 septembre 2021

\section{(c) (1) ()}

Études finno-ougriennes est mis à disposition selon les termes de la Licence Creative Commons Attribution - Pas d'Utilisation Commerciale 4.0 International. 


\section{Eda Kalmre : The Human Sausage Factory. A Study of Post-War Rumor in}

\section{Tartu}

[La fabrique de saucisses humaines. Étude d'une rumeur d'après-guerre à Tartu], Amsterdam-New York, 2013, x+180 p.

\section{Véronique Vincent-Campion}



1 Classant des textes pour les Archives de Folklore d'Estonie, Eda Kalmre remarqua en 2001 que beaucoup « racontaient l'histoire d'une fabrique de saucisses humaines à Tartu dans les années d'après-guerre ». Lorsque, dans un entretien publié le 
21 décembre 2001 dans la presse, elle «se référa à ces textes comme à une évidente histoire d'horreur» (p.3), plusieurs personnes assurèrent que ceci n'était pas du folklore, car eux, ou leurs parents, avaient vu la fabrique, et bien d'autres gens également à cette époque. Ce livre décrit et situe dans leur contexte les nombreux entretiens qui s'en suivirent. Les citations de ces informateurs sont agréablement réparties tout au long de l'ouvrage. Évidemment, la description des détails est liée à la croyance à la véracité de l'histoire. "Ils avaient vu des cheveux humains, ou simplement des poils de porcs, des vêtements d'enfants ou simplement des chiffons » (p. 5). La moitié des informateurs adhèrent à la véracité de l'histoire.

2 Eda Kalmre remarque combien l'histoire de la fabrique de saucisses humaines entraînait de sens et d'informations. "En même temps que cette vieille histoire, les gens me racontaient l'histoire de leurs vies - tout l'ensemble de leurs sentiments et souvenirs resurgissait. Pour moi cet incident qui avait été oublié devenait, à travers les histoires de mes informateurs, un guide de la période d'après-guerre et des univers des gens qui vivaient alors » (p. 5).

3 Se référant à des travaux antérieurs de folkloristes sur ce thème (Kõiva 1998) et à des récits de rumeurs proches (Brednich 1991, p. 100-104), Eda Kalmre explique le but de son livre : «il vise à observer la tradition comme un processus qui peut prendre des sens très divers et des degrés différents ». Son hypothèse est que ces rumeurs sont des histoires « caractérisées par une remarquable synthèse de la réalité et de l'imagination mythologique » (p. 24).

Dans l'évocation des temps troublés que vivait la cité de Tartu lorsque sont apparues les rumeurs de la fabrique de saucisses humaines, les illustrations sont intelligemment utilisées dans le livre. Ainsi, chaque chapitre est suivi d'un ensemble de trois photographies illustrant un monument ou un point remarquable de la ville avant (dans leur gloire), ensuite (en ruines), et après (reconstruits ou transformés). Le chapitre 1 (p. 31-37) parle des rumeurs de cannibalisme et présente les sources antérieures. Le chapitre 2 (p. 41-62) situe la rumeur de la fabrique de saucisses humaines parmi les images d'après-guerre de la violence et du mal. Le chapitre 3 (p. 65-84) analyse les relations antagonistes opposant les Estoniens aux nombreux « autres» (Russes, Juifs, Estoniens rentrant de Russie, etc.). Le chapitre 4 (p. 87-102) élargit vers les rumeurs de contamination alimentaire et présente la rumeur de la fabrique de saucisses humaines comme une critique du système économique soviétique. Le chapitre 5 (p. 105-128) parle des significations de la rumeur de la fabrique de saucisses humaines au XXIe siècle. Le chapitre 6 (p. 131-134) conclut en analysant le rôle de la rumeur comme métaphore de la vérité sociale.

5 Eda Kalmre explique comment « la violence et le mal qui s'étaient infiltrés dans Tartu [...] ont été considérés comme synonymes de la fabrique de saucisses humaines ». Par cette histoire, la réalité était reconstruite, l'horreur était nommée, et cette application du principe de Rumpelstilskin (Ellis 2003) - le nain du conte de Grimm qui perd tous ses pouvoirs maléfiques quand on le nomme - donnait aux narrateurs un sentiment de contrôle de la situation, ainsi expliquée. "L'époque était si terrible que tout était possible, même la vente de saucisses faites de chair humaine» (p. 62). Au sujet de la persistance de l'histoire, elle conclut: "le monde décrit dans ces histoires était si puissant et si influent qu'il a créé un environnement qui continue à fonctionner et à influencer les souvenirs et les émotions des gens, même aujourd'hui »(p.134). Ce livre important, toujours de ton modéré, est remarquable dans son évocation des temps 
difficiles qu'a vécu l'Estonie à la fin des années quarante et aujourd'hui. Son analyse en profondeur aidera le lecteur à comprendre la persistance de rumeurs proches dans de nombreuses sociétés aujourd'hui. Ces rumeurs ne sont généralement pas notées, mais les médias y font brièvement allusion lorsqu'un lynchage dont les victimes sont «nonindigènes » survient (cas de Nosy-Bé, Madagascar, octobre 2013).

\section{BIBLIOGRAPHIE}

BREDNICH Rolf Wilhelm, 1991, Die Maus im Jumbo-Jet. Neue sagenhafte Geschichten von heute, Munchen: Beck.

ELLIS Bill, 2003, Aliens, Ghosts and Cults: Legends we Live, Jackson: University Press of Mississippi: XV. KõIVA Mare, 1998, “Bloodsuckers and Human Sausage Factories”, FOAFTale News, 43, http:// www.folklore.ee/FOAFtale/ftn43.htm

\section{INDEX}

Index géographique : Estonie, Tartu motsclesru УЖАС, КАННИБАЛИЗН motscleset horror, inimesöömine Keywords : Horror, Cannibalism Mots-clés : horreur, cannibalisme Thèmes : études de folklore Index chronologique : XXe siècle nomsmotscles Estoniens, Russes 